\title{
IMPORTANCE OF EQUILIBRATION TIME IN THE PARTITIONING AND TOXICITY OF ZINC IN SPIKED SEDIMENT BIOASSAYS
}

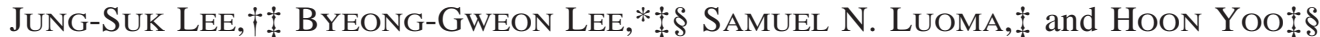 \\ $\dagger$ NeoEnBiz Company, Seoul, Republic of Korea \\ ¥U.S. Geological Survey, 345 Middlefield Rd, Menlo Park, California 94025 \\ $\S$ Department of Oceanography, Chonnam National University, 300 Yongbong-Dong, Kwang-Ju 500-757, Republic of Korea
}

(Received 25 March 2003; Accepted 24 June 2003)

\begin{abstract}
The influences of spiked Zn concentrations (1-40 $\mu \mathrm{mol} / \mathrm{g})$ and equilibration time ( $\sim 95 \mathrm{~d})$ on the partitioning of $\mathrm{Zn}$ between pore water (PW) and sediment were evaluated with estuarine sediments containing two levels $(5$ and $15 \mu \mathrm{mol} / \mathrm{g})$ of acid volatile sulfides (AVS). Their influence on Zn bioavailability was also evaluated by a parallel, 10-d amphipod (Leptocheirus plumulosus) mortality test at 5,20, and $85 \mathrm{~d}$ of equilibration. During the equilibration, AVS increased (up to twofold) with spiked Zn concentration ([Zn]), whereas Zn-simultaneously extracted metals ([SEM]; Zn with AVS) remained relatively constant. Concentrations of $\mathrm{Zn}$ in PW decreased most rapidly during the initial $30 \mathrm{~d}$ and by 11 - to 23 -fold during the whole 95 -d equilibration period. The apparent partitioning coefficient ( $K_{\mathrm{pw}}$, ratio of [Zn] in SEM to PW) increased by 10- to 20-fold with time and decreased with spiked $[\mathrm{Zn}]$ in sediments. The decrease of PW [Zn] could be explained by a combination of changes in AVS and redistribution of $\mathrm{Zn}$ into more insoluble phases as the sediment aged. Amphipod mortality decreased significantly with the equilibration time, consistent with decrease in dissolved [Zn]. The median lethal concentration (LC50) value $(33 \mu \mathrm{M})$ in the second bioassay, conducted after $20 \mathrm{~d}$ of equilibration, was twofold the LC50 in the initial bioassay at $5 \mathrm{~d}$ of equilibration, probably because of the change of dissolved $\mathrm{Zn}$ speciation. Sediment bioassay protocols employing a short equilibration time and high spiked metal concentrations could accentuate partitioning of metals to the dissolved phase and shift the pathway for metal exposure toward the dissolved phase.
\end{abstract}

Keywords-Zinc Toxicity Equilibration time Sediment aging Acid volatile sulfides

\section{INTRODUCTION}

Aquatic sediments in industrialized areas can contain concentrations of metals that are orders of magnitude higher than background levels [1]. Because metal-contaminated sediments pose a threat to resident benthic organisms [2-4], a primary goal of managing contaminated sediments is to protect food webs from that threat. Sediment bioassays are commonly employed for evaluating the threshold concentrations at which specific metals have adverse effects on test organisms. Bioassays can also aid in understanding the processes that influence partitioning and bioavailability of metals in sediments. However, important uncertainties remain in extrapolating spiked-sediment bioassay results unambiguously across a range of conditions in nature [5]. In the present study, we illustrate that the metal concentrations and equilibration time used for bioassay can be critical in determining the partitioning of metals to different binding phases of sediment, subsequent acute toxicity to sediment-dwelling organisms, and thus, the reliability of extrapolations from sediment bioassays to nature.

A growing body of work has demonstrated that understanding uptake routes of metals to benthic organisms from contaminated sediments is critical to determining metal bioavailability from sediments [6-10]. Some contradictory results are observed among studies concerning major metal exposure routes (e.g., pore water [PW] vs dietary metals) [8,11-14]. Most equilibrium partitioning-based studies contend that PW metal is the dominant bioavailable pool in sediment $[12,15,16]$. Another body of work has employed laboratory microcosm studies, field transplantation experiments, or biokinetic models to demonstrate that dietary uptake from contaminated sedi-

* To whom correspondence should be addressed (blee@chonnam.ac.kr). ments and food particles is a major route of metal exposure for various marine invertebrates, especially in moderately contaminated conditions [6,7,17-19]. Differences in experimental protocols make it difficult to compare among these contradictory studies. However, one major comparable difference among studies, as well as between laboratory studies and field situations, is how the metal contaminants are introduced to sediments before bioassay.

Many laboratory studies employ a protocol that exposes sediments to a spike of dissolved, but surface-reactive, metal and then equilibrating the slurry for days before the bioassay. Metal contaminants in nature, however, are often introduced gradually and over a much longer period; therefore, these contaminants have long equilibration times with sediments. In a reanalysis of previous studies (e.g., [12,16,20,21]), Lee et al. [10] suggested that the apparent partition coefficient (ratio of sediment to PW metal concentration) of $\mathrm{Cd}, \mathrm{Ni}$, and $\mathrm{Zn}$ tends to decrease with spiked metal levels and increase with metalsediment equilibration time. It is possible that high concentrations of dissolved metals introduced to sediment slurries can initially oversaturate the available binding sites on sediment surfaces until exchange reactions re-equilibrate partitioning [22]. Although numerous studies [10,23-26] have demonstrated effects of various geochemical parameters (e.g., acid volatile sulfide [AVS], $\mathrm{pH}$, redox potential, organic content, salinity, etc.) on metal partitioning in sediments, the effects of metal-sediment equilibration time on metal partitioning remain poorly understood.

If the degree of metal contamination and metal-sediment equilibration time influences directly the partitioning of metals between PW and sediment, they could also influence the bioavailability and toxicity of metals in contaminated sediments. 
In fact, Sae-Ma et al. [27] reported that bioaccumulation and mortality of midge (Chironomus tentans) exposed to $\mathrm{Cd}$ spiked soils decreased with storage time (up to $120 \mathrm{~d}$ ) of the experimental sediments. Although a few studies [27-29] have demonstrated reduction in bioavailability with metal-sediment equilibration time, this change in bioavailability has not been systematically linked to changes in metal geochemistry. Furthermore, the actual cause of reduction in bioavailability has rarely been explained.

In the present study, the influence of the equilibration time of $\mathrm{Zn}$ introduced to estuarine sediment particles on partitioning and toxicity was evaluated over $95 \mathrm{~d}$. We tried to relate the temporal change of geochemical parameters, such as AVS, weak-acid extractable $\mathrm{Zn}$, and pore-water $\mathrm{Zn}$ concentration (PW $[\mathrm{Zn}]$ ), to that of mortality of test animals. For simultaneous sediment toxicity test, estuarine amphipods (Leptocheirus plumulosus) were exposed for $10 \mathrm{~d}$ to $\mathrm{Zn}$-spiked sediments after 5, 20, or $85 \mathrm{~d}$ of equilibration. The relative concentrations of reactive sulfides called AVS (extracted by $1 \mathrm{~N}$ $\mathrm{HCl}$ and typically composed of amorphous iron sulfides) and simultaneously extracted metals (SEM) with AVS in sediments [SEM - AVS] can control dissolved metal concentrations in PW [15]. So, a range of AVS and Zn-SEM in sediments was employed to investigate the dynamic interaction of these geochemical parameters with equilibration time.

\section{MATERIALS AND METHODS}

\section{Sediment manipulation}

The experimental sediment containing approximately 30 $\mu \mathrm{mol} / \mathrm{g}$ of AVS was collected from a mud flat near Palo Alto (CA, USA) [30]. The collected sediment was screened through 1-mm nylon mesh at the site to remove macroinvertebrates. Mean particle size was $8.1 \phi$ (phi), and mean sand, silt, and clay contents, as analyzed by the pipetting method [31], were $0.4,43.8$, and $55.8 \%$, respectively. Loss on ignition for $5 \mathrm{~h}$ at $450^{\circ} \mathrm{C}$ was $7.7 \% \pm 0.7 \%$ (mean \pm standard deviation [SD], $n$ $=6)$.

After being brought to the laboratory, a portion of the collected sediment was manipulated to achieve two nominal AVS concentrations ( 5 and $15 \mu \mathrm{mol} / \mathrm{g}$ ) according to an established protocol [10]. Briefly, the sediment was mixed with an equivalent volume of deoxygenated saline water (20 practical salinity units [psu]) and divided into two batches. One batch of the sediment was kept in a closed container and purged with $\mathrm{N}_{2}$ gas periodically. The remaining sediment was oxidized by bubbling continuously with air for one week. The AVS concentration after one week of aeration decreased to approximately $1 \mu \mathrm{mol} / \mathrm{g}$. The oxidized and the remaining anoxic sediments $(\sim 30 \mu \mathrm{mol} / \mathrm{g})$ were mixed at appropriate ratios to achieve two nominal AVS levels (5 and $15 \mu \mathrm{mol} / \mathrm{g}$ ).

Following the AVS manipulation, the experimental sediments (containing $\sim 1.2 \mu \mathrm{mol} \mathrm{Zn} / \mathrm{g}$ ) were mixed with an appropriate volume of $\mathrm{Zn}$ stock solution to achieve nominal $\mathrm{Zn}$ concentrations of $10,20,30$, and $40 \mu \mathrm{mol} / \mathrm{g}$ for the low-AVS ( $5 \mu \mathrm{mol} / \mathrm{g}$ ) series and $10,20,40$, and $50 \mu \mathrm{mol} / \mathrm{g}$ for the highAVS $(15 \mu \mathrm{mol} / \mathrm{g})$ series sediments. The Zn stock solution was prepared by dissolving $\mathrm{ZnCl}_{2}$ in deoxygenated, deionized water. Additionally, the control sediments without $\mathrm{Zn}$ addition were included for each of two AVS series sediments. Following vigorous mixing with an electric mixer, the $\mathrm{Zn}$-spiked and control sediments were kept in closed polyvinylchloride bags purged with $\mathrm{N}_{2}$ gas and stored at $20 \pm 1^{\circ} \mathrm{C}$ during the entire experimental period.
Aliquots of the stored sediments were removed from each treatment $4 \mathrm{~d}$ before the beginning of the bioassays (at $t=5$, 20 , and $85 \mathrm{~d}$ ). The removed sediments were mixed well, and $300 \mathrm{ml}$ were transferred to four replicate, 1-L glass beakers. Three beakers were used for bioassay replicates and one for chemical analysis. The transferred sediments were allowed to consolidate for $3 \mathrm{~d}$ in the beakers. The overlying water was then decanted, $700 \mathrm{ml}$ of aerated seawater (20 psu) added into each beaker, and the sediments allowed to equilibrate for another day before bioassay.

\section{Bioassay procedure}

A 10-d amphipod sediment toxicity test $[32,33]$ was used to evaluate the influence of equilibration time on the acute toxicity of spiked $\mathrm{Zn}$ in sediments. The estuarine amphipod Leptocheirus plumulosus (approximately one month old) was obtained from laboratory culture and maintained in a salinity of $20 \mathrm{psu}$ at $20^{\circ} \mathrm{C}$. At the beginning of each bioassay (at $t=$ 5, 20, and $85 \mathrm{~d}$ ), 20 individual amphipods (length, 0.6-1.0 $\mathrm{mm}$ ) were transferred to each of the four beakers. Each beaker contained previously consolidated sediments that were equilibrated with overlying water. The overlying water was continuously aerated, and test chambers containing beakers were illuminated for $24 \mathrm{~h}$. Water quality (temperature, salinity, dissolved oxygen, $\mathrm{pH}$, and total ammonia) was monitored at $t=$ 0,5 , and $10 \mathrm{~d}$ of bioassay and met the recommended criteria for amphipod toxicity test in all cases [33]. Total ammonia concentration in the overlying water, sampled at $3 \mathrm{~cm}$ above the sediments, was always less than $100 \mu \mathrm{M}$, which is far below the acute toxicity concentration for this species [33]. Following 10-d exposure, live animals were collected from each of three experimental beakers by sieving sediments through $0.6-\mathrm{mm}$ mesh. The remaining beaker was used for the later geochemical analysis.

Separate 96-h, water-only $\mathrm{Cd}$ and $\mathrm{Zn}$ toxicity tests were conducted using L. plumulosus in 20 -psu seawater at $20^{\circ} \mathrm{C}$. The Cd toxicity test was done as a positive control to compare sensitivity of the test animals used for each of three bioassays. Mean 96-h median lethal concentration (LC50) estimates (12 $\pm 0.2 \mu \mathrm{M})$ for the three concurrent $\mathrm{Cd}$ reference toxicant tests conducted in conjunction with the spiked-sediment bioassays were not significantly different, indicating similar sensitivity to metals among the batches of test organisms used. The LC50 values from the water-only $\mathrm{Zn}$ toxicity test would be compared later to the LC50 values for PW Zn from each of the three sediment bioassays.

Sediment samples for chemical analysis (AVS, SEM, and PW) were collected twice, at the beginning and end of each $10-\mathrm{d}$ bioassay, from the beaker dedicated to chemical analysis. This sampling scheme resulted in six sediment-sampling events (at $t=5,15,20,30,85$, and $95 \mathrm{~d}$ ). The sediment in the beaker was homogenized with a plastic spatula after the overlying water was decanted. Following the homogenization, approximately $20 \mathrm{ml}$ of sediment were taken using a plastic syringe and immediately analyzed for AVS and SEM with an established method (see below). Approximately $40 \mathrm{ml}$ of sediment were transferred to a 50-ml centrifuge tube and spun for $30 \mathrm{~min}$ at $2,500 \mathrm{~g}$, and then the supernatant was filtered with a $0.45-\mu \mathrm{m}$ syringe filter. The filtrate was acidified immediately with Ultrex ${ }^{\circledR}$ (Baker, Phillipsberg, NJ, USA) $\mathrm{HCl}$ to a $\mathrm{pH}$ of 1 to 2 and used later for PW Zn analysis. Two replicate samples were taken from each treatment for AVS, SEM, and PW Zn analysis. 


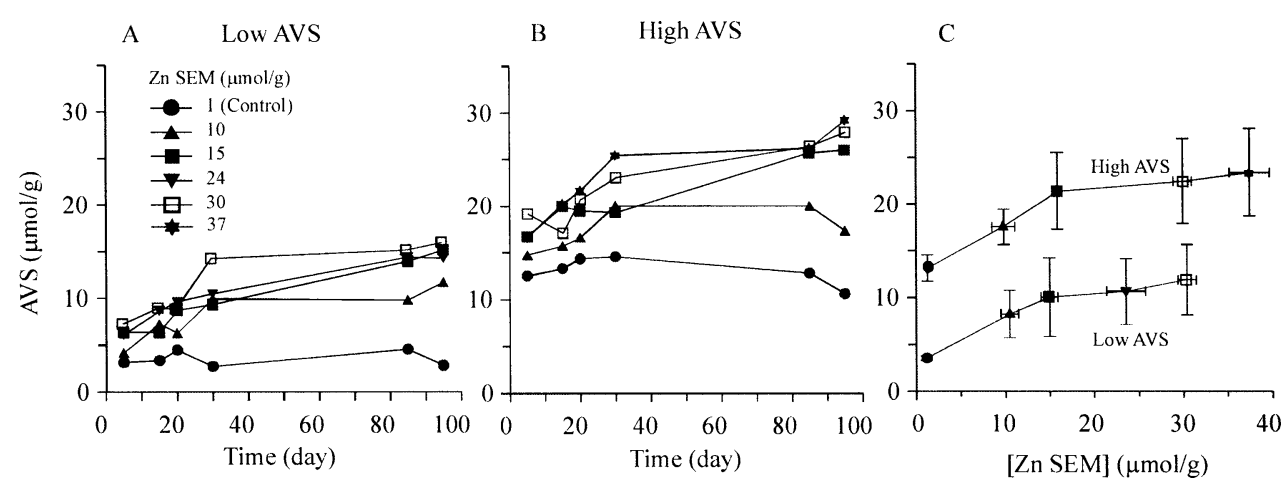

Fig. 1. Variation of acid volatile sulfide (AVS) with sediment-Zn equilibration time in low-AVS (A) and high-AVS (B) series and with Znsimultaneously extracted metals (SEM) with AVS (C). Weak acid extractable Zn concentration [Zn-SEM] in low-AVS series increased from 1

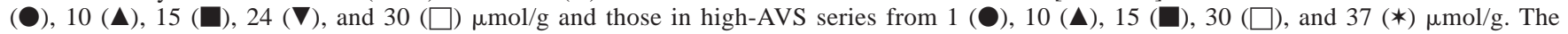
AVS value at each sampling time represents the mean of two replicate measurements. The difference between two measurements was mostly less than 20\%. Relationship between AVS and Zn-SEM in Zn-contaminated sediments in low- and high-AVS series was from the time-averaged values; error bars represents one standard deviation of AVS and Zn-SEM $(n=6)$.

\section{Analytical procedure}

The experimental containers and glassware used for sediment handling, chemical analysis, and sample storage were acid washed $(1 \mathrm{~N} \mathrm{HCl})$, then soaked in $\mathrm{N}_{2}$-purged deionized water for one week. The sediment samples were handled under a glove bag filled with $\mathrm{N}_{2}$ gas. The AVS analysis was conducted by an $\mathrm{N}_{2}$ purge and trap method using an ion-specific sulfide electrode within a week of sample collection [34,35]. The detailed analytical procedures are described elsewhere [12]. Metal concentrations in SEM, metal extracts from total sediment digestion $\left(\mathrm{HF}-\mathrm{HClO}_{4}-\mathrm{HNO}_{3}\right)$, and $\mathrm{PW}$ samples were determined with inductively coupled argon plasma-atomic emission spectroscopy and/or flame-atomic emission spectroscopy. Pore-water samples were diluted 10-fold with $0.1 \mathrm{~N}$ ultrapure nitric acid (to mitigate chloride interference) before analysis. The analytical quantification limit (mean $+10 \mathrm{SD}$ of procedure blank $\times$ dilution factor) for PW $\mathrm{Zn}$ was $1.5 \mu \mathrm{M}$.

\section{Data analysis}

The AVS, Zn-SEM, the molar difference between SEM with with AVS and AVS in sediments, [SEM - AVS], and PW [Zn] data were analyzed by multiway analysis of variance using the Statistica ${ }^{\circledR}$ (StatSoft, Tulsa, OK, USA) package to test the effects of equilibration time and of AVS and SEM levels on the biogeochemical parameters. Dry weight-based concentrations were used for all sediment data. The [SEM AVS] values were calculated by the difference between $\mathrm{Zn}$ SEM and AVS [10,12]. The LC50 values for 96-h, water-only $\mathrm{Cd}$ and $\mathrm{Zn}$ tests and 10-d sediment tests were calculated using the trimmed Spearman-Karber method [36]. Limited statistical analyses were done for PW [Zn] data, because many data were under the detection limit. Statistical significance was set at $p$ $=0.05$ unless otherwise noted. Mortality data for the amphipod were analyzed by two-way analysis of variance to test the effects of Zn-SEM and equilibration time for both low- and high-AVS series treatments.

\section{RESULTS}

\section{Geochemistry of sediment}

The AVS in all sediments was significantly influenced by both spiked $\mathrm{Zn}$ concentration and equilibration time $(p<$ 0.001) (Fig. 1). The AVS generally increased with equilibration time in the $\mathrm{Zn}$-spiked sediments but remained relatively con- stant over time in the control sediments. The concentration of AVS changed most rapidly during the initial $30 \mathrm{~d}$. The range of measured AVS at the beginning of equilibration $(t=5 \mathrm{~d})$ was 3 to $7 \mu \mathrm{mol} / \mathrm{g}$ in the low-AVS series and 13 to 19 $\mu \mathrm{mol} / \mathrm{g}$ in the high-AVS series, close to their nominal values ( 5 and $15 \mu \mathrm{mol} / \mathrm{g}$ ). At the end of the experiment, AVS ranged from 3 to $16 \mu \mathrm{mol} / \mathrm{g}$ in the low-AVS series and from 13 to $30 \mu \mathrm{mol} / \mathrm{g}$ in the high-AVS series. The AVS also increased with $\mathrm{Zn}$-SEM in both series (Fig. 1C).

The Zn-SEM in sediments was little influenced either by AVS or by equilibration time $(p>0.05)$. Mean Zn-SEM ( $n$ $=12$ ) over the ranges of AVS and equilibration time was 1.2 $\pm 0.1 \mu \mathrm{mol} / \mathrm{g}$ for control and $9.8 \pm 1.3,15 \pm 1,24 \pm 1,30$ \pm 2 , and $37 \pm 2 \mu \mathrm{mol} / \mathrm{g}$ in sediments with nominal $\mathrm{Zn}$ level of $10,20,30,40$, and $50 \mu \mathrm{mol} / \mathrm{g}$, respectively. Mean recoveries of $\mathrm{Zn}$-SEM (ratio of SEM to total extractable $\mathrm{Zn}$ ) were $57 \pm$ $10 \%(n=12)$ for control sediments and $87 \pm 6 \%(n=48)$ for all the Zn-spiked sediments.

Pore water $[\mathrm{Zn}]$ increased with spiked $\mathrm{Zn}$ concentrations, as expected. Pore water [Zn] decreased significantly with equilibration time, and its decrease was most apparent during the initial $30 \mathrm{~d}$ of equilibration (Fig. 2). Pore water [ $\mathrm{Zn}]$ decreased more in the high-AVS series (decrease of 23-fold) than in the low-AVS series (decrease of 11-fold) at the end of the 95-d equilibration period. This was least obvious in the sed-

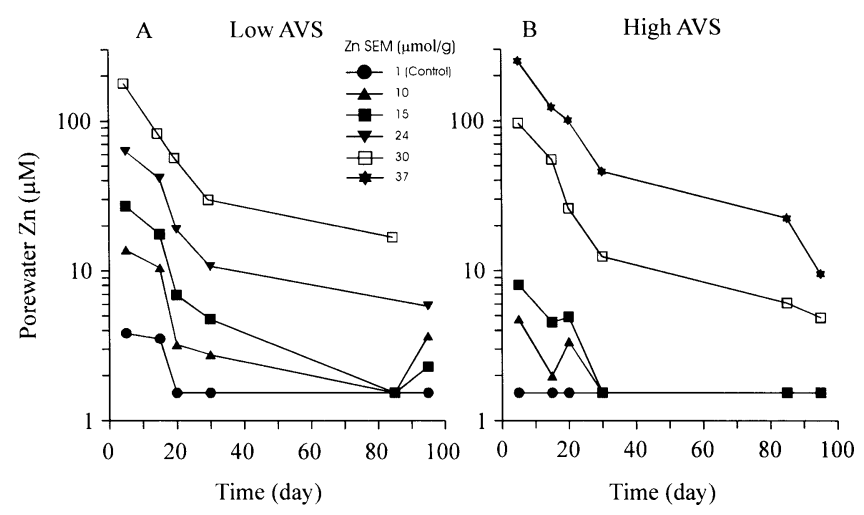

Fig. 2. Variation of pore-water $\mathrm{Zn}$ concentrations with sediment equilibration time in low-acid volatile sulfide (AVS) (A) and high-AVS (B) series (see Fig. 1 for symbols). SEM = simultaneously extracted metals with AVS. 

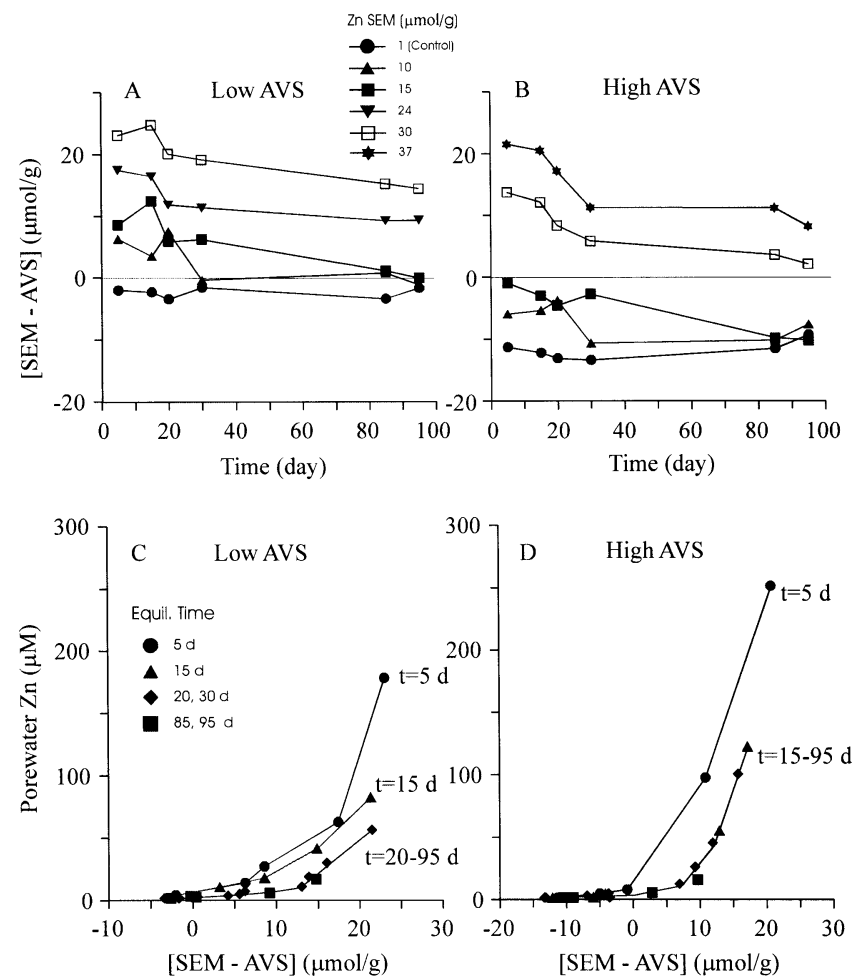

Fig. 3. Variation of [simultaneously extracted metals (SEM) - acid volatile sulfide (AVS)] with sediment equilibration time in low-AVS (A) and high-AVS (B) series. Relationship between pore-water Zn concentrations and [SEM - AVS] in low-AVS (C) and high-AVS (D) series at the different equilibration time is also shown.

iments with lower Zn-SEM ( $<15 \mu \mathrm{mol} / \mathrm{g}$ ), because some PW [Zn] were below the detection limit $(1.5 \mu \mathrm{M})$.

The patterns of [SEM - AVS] variation over time reflected the changes in AVS, because SEM changed little over time (Fig. 3, A and B). The [SEM - AVS] declined most during the first $30 \mathrm{~d}$ of equilibration, reflecting the rapid increase of AVS during this period, and remained relatively stable thereafter. The PW [Zn] increased generally with [SEM - AVS], as expected from the AVS normalization approach. The PW [Zn] to [SEM - AVS] relationship had changed with equilibration time; for a given [SEM - AVS] value, PW [Zn] decreased with equilibration time (Fig. 3, C and D).

The apparent partitioning coefficient $\left(K_{\mathrm{pw}} ; \mathrm{L} / \mathrm{kg}\right)$ of $\mathrm{Zn}$, defined as the ratio of $\mathrm{Zn}$ concentrations in SEM to PW, increased by 10 - to 20 -fold with equilibration time but decreased with spiked [Zn] (Fig. 4, A and B). The results suggest that the longer sediment aged or the lower the spiked $[\mathrm{Zn}]$, the more $\mathrm{Zn}$ partitioned proportionally to the sediment particles than to PW. The apparent partitioning coefficient decreased with [SEM - AVS] when [SEM - AVS] was greater than zero and increased with equilibration time for a given [SEM - AVS] (Fig. 4, C and D).

\section{Bioassays}

The mortality of amphipods exposed to sediments for 10 $\mathrm{d}$ at day 5, 20, or 85 of $\mathrm{Zn}$-sediment equilibration were compared to [SEM - AVS] (Fig. 5) or PW [Zn] (Fig. 6). The mortality of amphipods increased with [SEM - AVS] but was not significantly different from controls when [SEM - AVS] was less than zero (Fig. 5). The mortality was significantly reduced as the equilibration time increased. The reduction of toxicity was most apparent when comparing bioassay results
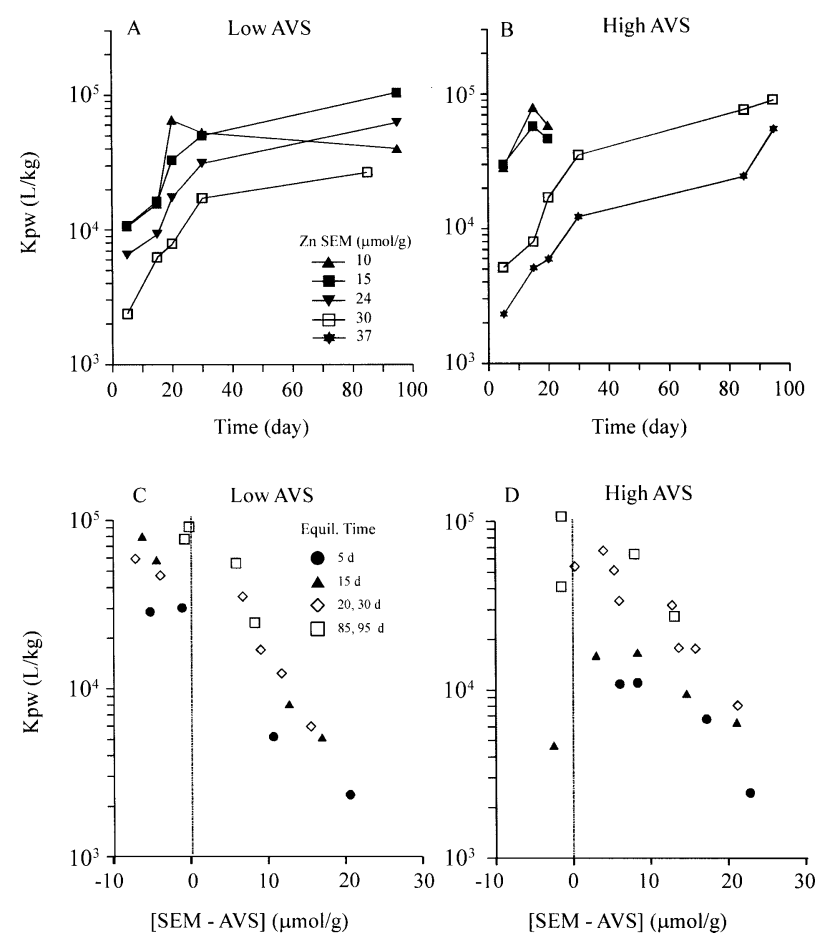

Fig. 4. Variation of apparent partitioning coefficient of $\mathrm{Zn}\left(K_{\mathrm{pw}}\right)$ with sediment equilibration time (A and $\mathbf{B}$ ) or with [simultaneously extracted metals (SEM) - acid volatile sulfide (AVS)] in low- and highAVS series at the different equilibration time $(\mathbf{C}$ and $\mathbf{D})$. Some $K_{\mathrm{pw}}$ in high-AVS series could not be calculated, because the pore-water $\mathrm{Zn}$ concentrations decreased below the detection limit. Decimal notation of exponential form is used for $\mathrm{y}$ axis scale.

conducted after 5-d equilibration to those after 20 -d equilibration (Fig. 5). Most individuals survived at 85-d equilibration even when [SEM - AVS] was much greater than zero.

Mortality of amphipods was explained better by PW [Zn] than by [SEM - AVS] (Fig. 6). All the mortality data from both high- and low-AVS treatments could be pooled into one relationship with $\mathrm{PW}[\mathrm{Zn}$ ] for a given equilibration time (5 d or $>20 \mathrm{~d}$ ). Significant mortality always occurred when PW [Zn] was greater than $20 \mu \mathrm{M}$. The mortality was significantly more at an equilibration time of $5 \mathrm{~d}$ than at $20 \mathrm{~d}$ across the range of $\mathrm{PW}[\mathrm{Zn}]$, when significant mortality was observed.

\section{Leptocheirus plumulosus}

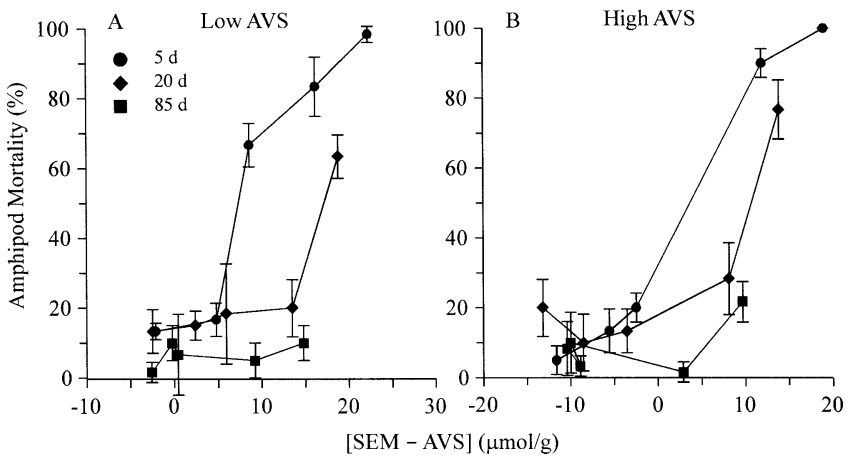

Fig. 5. Mortalities of amphipod Leptocheirus plumulosus with respect to [simultaneously extracted metals (SEM) - acid volatile sulfide (AVS)] in low-AVS (A) and high-AVS (B) series. Amphipods were exposed to control and $\mathrm{Zn}$-contaminated sediments for $10 \mathrm{~d}$ at the 5 $(\circlearrowleft), 20(\diamond)$, and $85 \mathrm{~d}(\boldsymbol{\square})$ of equilibration. Error bars represent one standard deviation $(n=3)$. 
Leptocheirus plumulosus

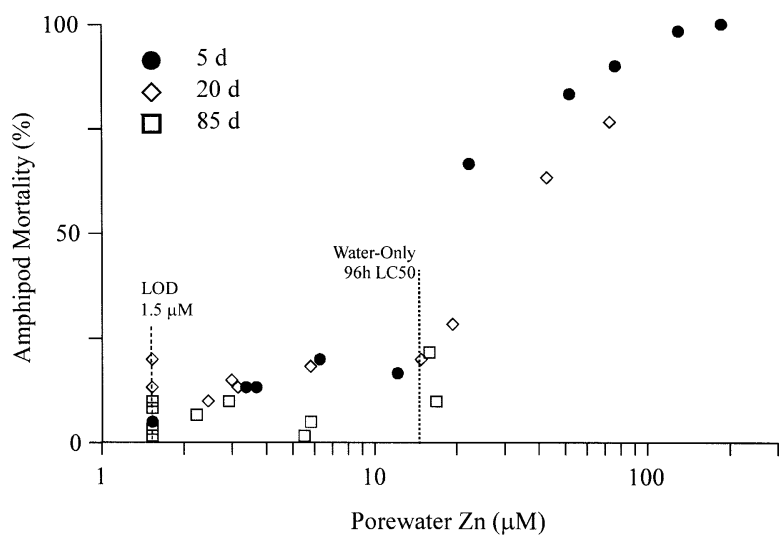

Fig. 6. The relationship between mortality of the amphipod Leptocheirus plumulosus and pore-water $\mathrm{Zn}$ concentrations. Amphipods were exposed to control and $\mathrm{Zn}$-contaminated sediments at the $5(\bullet)$, $20(\diamond)$, and $85(\square) \mathrm{d}$ of equilibration. Vertical lines represent either 96-h median lethal concentration (LC50) of water-only Zn exposure or the limit of detection (LOD) for pore-water $\mathrm{Zn}$.

From the relationship in Figure 6, the 10-d LC50 of dissolved $\mathrm{Zn}$ in PW at $5 \mathrm{~d}$ was estimated as $17 \mu \mathrm{M}$ (with a $95 \%$ confidence interval of $15-21 \mu \mathrm{M}$ ) and at $20 \mathrm{~d}$ as $33 \mu \mathrm{M}$ (with a $95 \%$ confidence interval of $27-40 \mu \mathrm{M}$ ). These values were higher than the mean 96-h LC50 value of $14 \mu \mathrm{M} \mathrm{Zn}$, independently determined with the water-only $\mathrm{Zn}$ toxicity test for L. plumulosus.

\section{DISCUSSION}

Previous bioassays involving metal-spiked sediments used a wide range of metal-sediment equilibration times and concentration levels. These differences in experimental protocols could have a critical influence on metal partitioning and, thereby, could affect toxicity to organisms exposed to the sediments. We have systematically demonstrated that both sediment aging and metal contamination levels are major controlling factors for metal partitioning between sediment particles and the dissolved phase and, thus, collectively influence acute toxicity to exposed benthic organisms. These results help to explain some of the discrepancies among the studies regarding routes of metal uptake from contaminated sediments $[8,13]$.

\section{Effect of equilibration time on metal partitioning}

The 20-fold decrease of PW [Zn] during $85 \mathrm{~d}$ of equilibration could be explained mainly by the redistribution of $\mathrm{Zn}$ from labile/weak-binding phases to more insoluble phases, including AVS, and other binding phases, such as metal oxides and organic matter. Among these binding phases, AVS is recognized as a dominant binding phase in the anoxic sediments, and its effect on PW metals is relatively well studied [37].

The influence of AVS relative to SEM on PW metals has been well established for several divalent metals, including $\mathrm{Zn}$ $[12,15,16,26]$. Typically, PW [Zn] is very low when [SEM AVS] is less than zero and increases exponentially with [SEM - AVS] when [SEM - AVS] is greater than zero. In the present study, the decrease of [SEM - AVS] with time, which resulted in a reduction of $\mathrm{PW}[\mathrm{Zn}]$, was largely controlled by the increase of AVS, because SEM was relatively constant over the equilibration period. The increase of AVS concentration ([AVS]) in Zn-contaminated sediments can be explained by sequestration of AVS (mostly in amorphous FeS) by $\mathrm{Zn}$. If
AVS could be rapidly converted from amorphous FeS to $\mathrm{ZnS}$ in the $\mathrm{Zn}$-spiked sediments, the slower oxidation rate of $\mathrm{ZnS}$ compared to that of FeS could result in the buildup of AVS that was observed. For example, Simpson et al. [24,38] demonstrated that $\mathrm{FeS}$ was rapidly oxidized in aerated waters whereas ZnS was kinetically stable for oxidation. Similarly, other studies also observed an increase of AVS on addition of divalent metals in sediments [12,39].

An increase of AVS alone, however, does not entirely explain the observed reduction of PW [Zn] with equilibration time. For a given [SEM - AVS], PW [Zn] decreased with equilibration time when [SEM - AVS] was greater than 0 (Fig. 3). Furthermore, in anoxic sediment, PW [Zn] continuously decreased with time even when [SEM - AVS] was less than zero. These results collectively suggest that some other processes were responsible for further reduction of $\mathrm{PW}$ [Zn]. One process, other than AVS sequestration of PW $[\mathrm{Zn}]$, that could be responsible for $\mathrm{PW}[\mathrm{Zn}$ ] reduction is redistribution of $\mathrm{Zn}$ from labile binding sites to more refractory sites. In fact, the greater extraction efficiency of SEM in Zn-spiked sediments compared to unspiked control sediments in the present study suggests that $\mathrm{Zn}$ in spiked sediments is more labile than in the control sediments, which probably had a much longer metal-sediment equilibration time in nature. Confirming this observation, Griscom et al. [40] showed in the sequential extraction of metals in sediment aged up to $35 \mathrm{~d}$ that the labile fraction of $\mathrm{Cd}, \mathrm{Co}, \mathrm{Se}$, and $\mathrm{Zn}$ decreased whereas the resistant fractions significantly increased with time. The labile fraction (i.e., low $K_{\mathrm{pw}}$ ) includes the adsorbed and exchangeable phases of metals bound on the sediment surface; the resistant phases (i.e., high $K_{\mathrm{pw}}$ ) include the hydrous iron or manganese oxides, organic matter, and mineralized fractions of sediments [41]. Other laboratory metal adsorption studies $[41,42]$ demonstrated that slower partitioning processes (e.g., physical and microbial transformation) followed the initial rapid adsorption of metals that occurred within a few days.

The level of spiked metal is another important factor affecting PW metal concentrations. An order of magnitude decrease occurred in $K_{\mathrm{pw}}$ of $\mathrm{Zn}$ as Zn-SEM or [SEM - AVS] increased (Fig. 4). One possibility is association of $\mathrm{Zn}$ with binding sites of progressively lower stability as the [Zn-SEM] increases. Consistent with this, adsorption isotherms predict nonlinearity at high adsorbate (metal) concentrations because of the saturation of binding sites on the particle surface $[22,43]$. Other laboratory studies also showed decreases in $K_{\mathrm{pw}}$ of $\mathrm{Cd}$, $\mathrm{Ni}$, and $\mathrm{Zn}$ with the increase of [SEM - AVS] in laboratoryspiked sediments [10].

\section{Bioavailability}

Bioavailability (expressed as acute toxicity) of spiked $\mathrm{Zn}$ in sediments was also reduced significantly with $\mathrm{Zn}$-sediment equilibration time. Other studies $[39,44]$ have also evaluated the role of temporal variation of AVS and SEM for bioavailability and other biological responses, but to our knowledge, they have not established the potential reasons for the variation. In the present study, the reduction in toxicity was best explained by the concurrent reduction of dissolved [Zn] as represented by $\mathrm{PW}[\mathrm{Zn}]$. In contrast, [SEM - AVS] was a less accurate indicator of bioavailability/toxicity, because the dissolved Zn to [SEM - AVS] relationship was changed by the equilibration time. However, the reduction of dissolved [Zn] as represented by PW could not explain all the reduction of $\mathrm{Zn}$ bioavailability over time. The increase in LC50 values 
of PW $\mathrm{Zn}$ in the sediment toxicity test by twofold during equilibration time suggests that the toxicity of dissolved $\mathrm{Zn}$ decreased over time. A plausible explanation for this observation could be that the $\mathrm{Zn}$ speciation of the dissolved phase had been changed over time. For example, a decrease in free $\mathrm{Zn}$ ion activity in PW, which could have occurred because of changes in concentrations and/or composition of dissolved $\mathrm{Zn}$ binding ligands (e.g., dissolved organic matter), might be responsible for reduced toxicity of PW Zn. Another possible explanation could be related to the variation of dissolved $\mathrm{Zn}$ concentration in overlying water, which was not measured in the present study.

It should be noted that the cause of mortality was assigned to dissolved $\mathrm{Zn}$ (either overlying water or PW Zn) rather than to PW Zn only. The dissolved [ $\mathrm{Zn}]$ in the overlying water was not determined in the present study. However, it is reasonable to assume that overlying water [ $\mathrm{Zn}]$ correlated and behaved similarly to PW [Zn], because [SEM - AVS] is a major cofactor controlling $[\mathrm{Zn}]$ in both overlying water and PW. Especially, the static renewal protocol employed in the present study could facilitate $\mathrm{Zn}$ to be equilibrated between PW and overlying water. Consistent with this idea, previous studies $[19,21]$ have demonstrated that metal concentrations in overlying water strongly correlate with PW metal concentrations.

Many earlier studies (e.g., [16]) have suggested that acute mortality of organisms exposed to metal-contaminated sediments is controlled by exposure to dissolved metals. Our results generally support the utility of AVS normalization for predicting no acute toxicity of animals exposed to metal-contaminated sediments when [SEM - AVS] is less than zero. It is important to recognize, however, that the strong correlation between dissolved $\mathrm{Zn}$ and acute toxicity does not preclude chronic effects from other routes of uptake, including exposure to metals via diet, at lower $\mathrm{Zn}$ concentrations. In fact, a growing body of evidence $[9,19,26,40,45]$ shows that bioaccumulation of metals in a variety of benthic invertebrates occurs when [SEM - AVS] is less than zero. Such results are little affected by the variation of [SEM - AVS]. Rather, bioaccumulation is related best to SEM concentrations and is best explained by ingestion of contaminated sediments $[9,26,45]$. One of the reasons for such results is that benthic invertebrates ingesting AVS-rich, pure-phase particles or anoxic sediments are able to assimilate metals with assimilation efficiencies similar to those for oxic particles [8,40,46]. A second reason, however, is that all such studies were conducted with lessthan-extreme metal concentrations and realistic partitioning approaches.

The toxicological significance of complex, chronic exposure conditions are only beginning to be understood (e.g., [47]). However, whether the measure is toxicity or contaminant uptake, both short equilibration times and high spiked metal concentrations in sediments will accentuate partitioning of metals disproportionately to the dissolved phase and increase the probability of exposure and/or toxicity via dissolved metals. If metals are introduced gradually into contaminated sediment, equilibrated over long time scales, and/or have concentrations that are not extreme, then partition coefficients will be high, and chronic exposures are the concern. Results derived from spiked-sediment bioassays do not necessarily provide accurate/relevant estimates of the risk for sediments in nature.

Acknowledgement-The authors thank two anonymous reviewers for many thoughtful suggestions. This work was supported in part by the
Toxic Substances Hydrology Program of the U.S. Geological Survey and by research and development funds granted to B.-G. Lee from the Korean Ministry of Marine and Fisheries.

\section{REFERENCES}

1. Daskalakis KD, O'Connor TP. 1995. Distribution of chemical concentrations in US coastal and estuarine sediment. Mar Environ Res 40:381-398.

2. Luoma SN, Carter JL. 1991. Effects of trace metals on aquatic benthos. In Newman MC, McIntosh AW, eds, Metal Ecotoxicology: Concept and Application. Lewis, Boca Raton, FL, USA, pp 261-300.

3. Bryan GW, Langston WJ. 1992. Bioavailability, accumulation, and effects of heavy metals in sediments with special reference to United Kingdom estuaries: A review. Environ Pollut 76:89131.

4. Hornberger MI, Luoma SN, Cain DJ, Parchaso F, Brown CL, Bouse RM, Wellise C, Thomson JK. 2000. Linking bioaccumulation and biological effects to changes in pollutant loads in South San Francisco Bay. Environ Sci Technol 34:2401-2409.

5. Luoma SN. 1996. The developing framework of marine ecotoxicology: Pollutants as a variable in marine ecosystems? $J$ Exp Mar Biol Ecol 200:29-55.

6. Luoma SN, Johns C, Fisher NS, Steinberg NA, Oremiand RS, Reinfelder JR. 1992. Determination of selenium bioavailability to a benthic bivalve from particulate and solute pathways. Environ Sci Technol 26:485-491.

7. Wang WX, Fisher NS, Luoma SN. 1996. Kinetic determinations of trace element bioaccumulation in the mussel Mytilus edulis. Mar Ecol Prog Ser 140:91-113.

8. Lee BG, Griscom SB, Lee JS, Luoma SN, Choi HJ, Koh CH, Fisher NS. 2000. Influence of dietary uptake and reactive sulfides on metal bioavailability from aquatic sediments. Science (Wash DC) 287:282-284.

9. Lee BG, Lee JS, Choi HJ, Luoma SN, Koh CH. 2000. Influence of acid volatile sulfides and metal concentrations on the bioavailability to marine invertebrates in contaminated sediments. Environ Sci Technol 34:4517-4523.

10. Lee JS, Lee BG, Choi HJ, Luoma SN, Koh CH, Brown CL. 2000. Influence of acid volatile sulfides and metal concentrations on metal partitioning in contaminated sediments. Environ Sci Technol 34:4511-4516.

11. Green AS, Chandler GT, Blood ER. 1993. Aqueous-, pore-water-, and sediment-phase cadmium: Toxicity relationships for a meiobenthic copepod. Environ Toxicol Chem 12:1497-1506.

12. Ankley GT, Di Toro DM, Hansen DJ, Berry WJ. 1996. Technical basis and proposal for deriving sediment quality criteria for metals. Environ Toxicol Chem 15:2056-2066.

13. Luoma SN, Fisher NS. 1997. Uncertainties in assessing contaminant exposure from sediments. In Ingersoll CG, Dillon T, Biddinger GR, eds, Ecological Risk Assessment of Contaminated Sediments. SETAC, Pensacola, FL, USA, pp 211-237.

14. Warren LA, Tessier A, Hare L. 1998. Modeling cadmium accumulation by benthic invertebrates in situ: The relative contributions of sediment and overlying water reservoirs to organism cadmium concentrations. Limnol Oceanogr 43:1442-1454.

15. Di Toro DM, Mahony JD, Hansen DJ, Scott KJ, Carlson AR, Ankley GT. 1992. Acid volatile sulfide predicts the acute toxicity of cadmium and nickel in sediments. Environ Sci Technol 26: 96-101.

16. Berry WJ, Hansen DJ, Mahony JD, Robson DL, Di Toro DM, Shipley BP, Rogers B, Corbin JM, Boothman WS. 1996. Predicting the toxicity of metal-spiked laboratory sediments using acid-volatile sulfide and interstitial water normalizations. Environ Toxicol Chem 15:2067-2079.

17. Munger C, Hare L. 1997. Relative importance of water and food as cadmium sources to an aquatic insect (Chaoborus punctipennis): Implications for predicting $\mathrm{Cd}$ bioaccumulation in nature. Environ Sci Technol 31:891-895.

18. Selck H, Forbes VE, Forbes TL. 1998. Toxicity and toxicokinetics of cadmium in Capitella sp. I: Relative importance of water and sediment as routes of cadmium uptake. Mar Ecol Prog Ser 164: $167-178$.

19. Lee JS, Lee BG, Yoo H, Luoma SN, Koh CH. 2001. Influence of reactive sulfide (AVS) and supplementary food on $\mathrm{Ag}, \mathrm{Cd}$, and $\mathrm{Zn}$ bioaccumulation in the marine polychaete Neanthes arenaceodentata. Mar Ecol Prog Ser 216:129-140. 
20. Sibley PK, Ankley GT, Cotter AM, Leonard EN. 1996. Predicting chronic toxicity of sediments spiked with zinc: An evaluation of the acid-volatile sulfide model using a life-cycle test with the midge Chironomus tentans. Environ Toxicol Chem 15:21022112 .

21. DeWitt TH, Swartz RC, Hansen DJ, McGovern D, Berry WJ. 1996. Bioavailability and chronic toxicity of cadmium in sediment to the estuarine amphipod Leptocheirus plumulosus. Environ Toxicol Chem 15:2095-2101.

22. Oakley SM, Nelson PO, Williamson KJ. 1981. Model of trace metal partitioning in marine sediments. Environ Sci Technol 15: 474-480.

23. Morse JW. 1994. Interactions of trace metals with authigenic sulfide minerals: Implications for their bioavailability. Mar Chem 46:1-6.

24. Simpson SL, Apte SC, Batley GE. 1998. Effect of short term resuspension events on trace metal speciation in polluted anoxic sediments. Environ Sci Technol 32:620-625.

25. Tessier A, Campbell PGC, Auclair JC, Bisson M. 1984. Relationships between the partitioning of trace metals in sediments and their accumulation in the tissues of the freshwater mollusk Elliptio complanata in a mining area. Can J Fish Aquat Sci 41: 1463-1472.

26. Hare L, Carignan R, Huerta-Diaz MA. 1994. A field study of metal toxicity and accumulation by benthic invertebrates; implications for the acid-volatile sulfide (AVS) model. Limnol Oceanogr 39:1653-1668.

27. Sae-Ma B, Meier PG, Landrum PF. 1998. Effect of extended storage time on the toxicity of sediment-associated cadmium on midge larvae (Chironomus tentans). Ecotoxicology 7:133-139.

28. Dillon TM, Moore DW, Jarvis AS. 1994. The effects of storage temperature and time on sediment toxicity. Arch Environ Contam Toxicol 27:51-53.

29. Beiras R, His E, Seaman MNL. 1998. Effects of storage temperature and duration on toxicity of sediments assessed by Crassostrea gigas oyster embryo bioassay. Environ Toxicol Chem 17: 2100-2105.

30. Cain DJ, Luoma SN. 1990. Influence of seasonal growth, age, and environmental exposure on $\mathrm{Cu}$ and $\mathrm{Ag}$ in a bivalve indicator, Macoma balthica, in San Francisco Bay. Mar Ecol Prog Ser 60: 45-55.

31. Folk RL. 1954. The distribution between grain size and mineral composition in sedimentary rock nomenclature. J Geol 23:1-12.

32. Schlekat CE, McGee BL, Reinharz E. 1992. Testing sediment toxicity in Chesapeake bay with the amphipod Leptocheirus plumulosus: An evaluation. Environ Toxicol Chem 11:225-236.

33. U.S. Environmental Protection Agency. 1994. Methods for assessing the toxicity of sediment-associated contaminants with es- tuarine and marine amphipods. EPA 600-R-94-025. Washington DC.

34. Allen HE, Fu G, Deng B. 1993. Analysis of acid-volatile sulfide (AVS) and simultaneously extracted metals (SEM) for the estimation of potential toxicity in aquatic sediments. Environ Toxicol Chem 12:1441-1453.

35. Lasorsa B, Casas A. 1996. A comparison of sample handling and analytical methods for determination of acid volatile sulfides in sediment. Mar Chem 52:211-220.

36. Hamilton MA, Russo RC, Thurston RV. 1977. Trimmed Spearman-Karber method for estimating median lethal concentrations in toxicity bioassays. Environ Sci Technol 11:714-719.

37. Morse JW, Millero FJ, Cornwell JC, Rickard D. 1987. The chemistry of the hydrogen sulfide and iron sulfide systems in natural waters. Earth-Sci Rev 24:1-42.

38. Simpson SL, Apte SC, Batley GE. 2000. Effect of short-term resuspension events on the oxidation of cadmium, lead, and zinc sulfide phases in anoxic estuarine sediments. Environ Sci Technol 34:4533-4537.

39. Liber K, Call DJ, Markee TP, Schmude KL, Balcer MD, Whiteman FW, Ankley GT. 1996. Effects of acid-volatile sulfide on zinc bioavailability and toxicity to benthic macroinvertebrates: A spiked-sediment field experiment. Environ Toxicol Chem 15: 2113-2125.

40. Griscom SB, Fisher NS, Luoma SN. 2000. Geochemical influences on assimilation of sediment-bound metals in clams and mussels. Environ Sci Technol 34:91-99.

41. Jannasch HW, Honeyman BD, Balistrieri LS, Murray JW. 1988. Kinetics of trace element uptake by marine particles. Geochim Cosmoschim Acta 52:567-577.

42. Nyffeler UP, Li YH, Santschi PH. 1984. A kinetic approach to describe trace-element distribution between particles and solution in natural aquatic systems. Geochim Cosmoschim Acta 48:15131522.

43. Bourg ACM. 1987. Trace metal adsorption modeling and particlewater interactions in estuarine environments. Cont Shelf Res 7: 1319-1332.

44. Boothman WS, Hansen DJ, Berry WJ, Robson DL, Helmstetter A, Corbin JM, Pratt SD. 2001. Biological response to variation of acid-volatile sulfides and metals in field-exposed spiked sediments. Environ Toxicol Chem 20:264-272.

45. Ingersoll CG, Brumbaugh WD, Dwyer JD, Kemble NE. 1994 Bioaccumulation of metals by Hyalella azteca exposed to contaminated sediments from the upper Clark Fork river, Montana. Environ Toxicol Chem 13:2013-2020.

46. Wang WX, Stupakoff I, Fisher NS. 1999. Bioavailability of dissolved and sediment-bound metals to a marine deposit-feeding polychaete. Mar Ecol Prog Ser 178:281-293.

47. Hook SE, Fisher NS. 2001. Sublethal effects of silver in zooplankton: Importance of exposure pathways and implications for toxicity testing. Environ Toxicol Chem 20:568-574. 